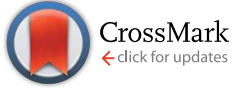

Cite this: RSC Adv., 2016, 6, 51562

\title{
Supramolecular block copolymer photovoltaics through ureido-pyrimidinone hydrogen bonding interactions $\uparrow$
}

\author{
Yen-Hao Lin, ${ }^{\text {ac }}$ Wanyi Nie, ${ }^{c}$ Hsinhan Tsai, ${ }^{\text {b }}$ Xiaoyi Li, ${ }^{\text {a }}$ Gautam Gupta, ${ }^{c}$ \\ Aditya D. Mohite ${ }^{c}$ and Rafael Verduzco*ab
}

A challenge in the development of bulk heterojunction organic photovoltaics (BHJ OPVs) is achieving a desirable nanoscale morphology. This is particularly true for polymer blend OPVs in which large-scale phase separation occurs during processing. Here, we present a versatile approach to control the morphology in polymer blend OPVs through incorporation of self-associating 4 2-ureido-4[1H]pyrimidinone (UPy) endgroups onto donor and acceptor conjugated polymers. These UPy functionalized polymers associate to form supramolecular block copolymers during solution blending and film casting. Atomic force microscopy measurements show that supramolecular associations can improve film uniformity. We find that the performance of supramolecular block copolymer OPVs improves from $0.45 \%$ to $0.77 \%$ relative to the non-associating conjugated polymer blends at the same $155^{\circ} \mathrm{C}$ annealing conditions. Impedance measurements reveal that UPy endgroups both increase the resistance for charge recombination and for bulk charge transport. This work represents a versatile approach to reducing large-scale phase separation in polymer-polymer blends and directing the morphology through supramolecular interactions.

Received 8th April 2016

Accepted 10th May 2016

DOI: 10.1039/c6ra09041a

www.rsc.org/advances separation in polymer blend OPVs can be reduced or suppressed through the use of high molecular weight polymers, ${ }^{5}$ low boiling point solvents, ${ }^{6}$ and polymers with compatibilizing side-chains. ${ }^{7-10}$ This work has resulted tremendous progress in polymer blend OPVs, with several recent examples of photoconversion efficiencies exceeding or near $7 \% .^{\mathbf{8 , 1 1 - 1 6}}$

In this work, we demonstrate an alternative approach to direct the morphology of polymer blend OPVs through the use of supramolecular hydrogen bonding interactions. Such interactions have been explored for in a variety of applications, including in organic electronic materials. ${ }^{17-21}$ Hydrogen bonding interactions have been implemented for improving the stability and directing the morphology of polymer/inorganic particle blends ${ }^{22,23}$ and to improve energy transfer between donor-acceptor polymers and dyes. ${ }^{24,25}$ Hydrogen bonding associations have also been implemented in polymer-fullerene OPVs $^{26,27}$ but to date have not been used in polymer blend OPVs.

Herein, we demonstrate supramolecular BHJ OPVs through the use of quadruple hydrogen bonding group 2-ureido- $4[1 \mathrm{H}]$ pyrimidinone (UPy). We study model systems comprised of UPy-functionalized poly(3-hexylthiophene) (P3HT) and UPy-

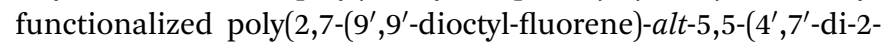
thienyl-2', $1^{\prime}, 3^{\prime}$-benzothiadiazole)) (PFTBT). These UPyfunctionalized polymers are used in the preparation of $\mathrm{BHJ}$ OPV devices comprised of polymer-polymer blends. We find that supramolecular interactions improve the performance of polymer-blend OPVs when the UPy endgroup is introduced. 
Atomic force microscopy (AFM) measurements indicate that the quadruple hydrogen bonding molecule give more uniform and finer morphologies under both $100{ }^{\circ} \mathrm{C}$ and $155{ }^{\circ} \mathrm{C}$ annealing temperatures. Impedance analysis under short circuit and illumination conditions reveals that the UPy endgroups increase resistance for charge recombination process at donoracceptor interface and increase bulk charge transport resistance across the active layer. This work demonstrates a versatile and generally applicable approach to reduce large-scale phase separation in polymer-polymer blends.

\section{Experimental}

\section{Materials}

Methyl isocytosine (MIC) was purchased from Sigma-Aldrich and dried under vacuum at $100{ }^{\circ} \mathrm{C}$ overnight before use. 2(6-Isocyanatohexylaminocarbonylamino)-6-methyl-4[1 $[H]$-pyrimidinone (UPy-isocyanate) $^{28}$ and 2,5-dibromo-3-hexylthiophene ${ }^{29}$ was prepared as described previously. All other reagents were purchased from Sigma-Aldrich and used as received.

Hydroxyl-end functionalized poly(3-hexylthiophene), P3HTOH. P3HT-OH was prepared using a procedure adapted from a previous report. ${ }^{30,31}$ In a $50 \mathrm{~mL}$ flask purged with nitrogen gas, 2,5-dibromo-3-hexylthiophene (1.9 g, $5.82 \mathrm{mmol}$ ) was dissolved in anhydrous THF ( $5 \mathrm{~mL})$, and the solution was stirred under nitrogen at $0{ }^{\circ} \mathrm{C}$ for 15 minutes. A solution of isopropyl magnesium chloride and $\mathrm{LiCl}(1.3 \mathrm{M})$ in $\mathrm{THF}(4.48 \mathrm{~mL}$, $5.82 \mathrm{mmol}$ ) was added, and the mixture was stirred for 2 hours. Next, $40 \mathrm{~mL}$ of THF was added to the reaction flask followed by the crude reaction solution containing chloro-[2-methyl-4-[6-tbutyldimethylsilyloxyethoxy]phenyl] 1,3-bis(diphenylphosphino)propane nickel(II) (0.049 mmol, $2 \mathrm{~mL})$. The solution was stirred for an hour and a half before quenching with $5 \mathrm{M} \mathrm{HCl}$ ( $2 \mathrm{~mL}, 10 \mathrm{mmol}$ ). TBAF ( $2 \mathrm{~mL}, 2 \mathrm{mmol}$ ) was then added to the reaction flask to remove the silane protecting group, and the reaction mixture was stirred overnight. The final mixture was collected by precipitation in $300 \mathrm{~mL}$ of chilled methanol and filtering. The filtered product was washed with acetone and hexanes and dried under vacuum. PS relative $\mathrm{Mw}$ (GPC): $11 \mathrm{~kg}$ $\mathrm{mol}^{-1}$, polydispersity $=1.05 .{ }^{1} \mathrm{H} \mathrm{NMR}\left(500 \mathrm{MHz}, \mathrm{CDCl}_{3}\right)$ (Fig. S1 $\dagger$ ), $\delta$ (ppm): 7.0 (Ar-H), 4.1 (Ar-O- $\left.\mathrm{CH}_{2}-\mathrm{CH}_{2}-\mathrm{OH}\right), 4.0$ (Ar$\left.\mathrm{O}-\mathrm{CH}_{2}-\mathrm{CH}_{2}-\mathrm{OH}\right), 2.8\left(\mathrm{Ar}-\mathrm{CH}_{2}-\right), 2.49\left(\mathrm{Ar}-\mathrm{CH}_{3}\right), 1.7\left(\mathrm{Ar}-\mathrm{CH}_{2}-\right.$ $\left.\mathrm{CH}_{2}-\right)$, 1.2-1.5 ( $\left.\mathrm{Ar}-\mathrm{CH}_{2}-\mathrm{CH}_{2}-\left(\mathrm{CH}_{2}\right)_{3}-\mathrm{CH}_{3}\right), 0.9\left(\mathrm{Ar}-\left(\mathrm{CH}_{2}\right)_{5}-\mathrm{CH}_{3}\right)$.

Hydroxyl-end functionalized poly $\left(2,7-\left(9^{\prime}, 9^{\prime}\right.\right.$-dioctyl-fluorene $)$ alt-5,5-(4',7'-di-2-thienyl-2' $\mathbf{1}^{\prime} \mathbf{1}^{\prime}, \mathbf{3}^{\prime}$-benzothiadiazole)), PFTBT-OH. $9^{\prime}, 9^{\prime}$-Dioctylfluorene-2', $7^{\prime}$-diboronic acid ester (506 mg, 0.9 mmol), 4,7-di-2'-(5'-bromo)-thienyl-2' ${ }^{\prime}, 1^{\prime}, 3^{\prime}$, -benzothiadiazole (407 mg, $0.89 \mathrm{mmol}$ ), tetrakis-(triphenyl-phosphine)palladium(0) (75 mg, $0.065 \mathrm{mmol}$ ), 4-bromobenzyl alcohol (16.8 $\mathrm{mg}, 0.09 \mathrm{mmol}$ ), and aliquot 336 (3 drops) were added to a Schlenk tube loaded with nitrogen-purged toluene $(25 \mathrm{~mL})$ and $2 \mathrm{M} \mathrm{Na}_{2} \mathrm{CO}_{3}$ aqueous solution $(10 \mathrm{~mL})$. The reaction was stirred in $90{ }^{\circ} \mathrm{C}$ oil bath for 1 day. 4-(Hydroxymethyl)phenylboronic acid pinacol ester $(157 \mathrm{mg}, 0.67 \mathrm{mmol})$ was added to the reaction tube and the solution was stirred for 1 day at $90{ }^{\circ} \mathrm{C}$. The crude product was collected by precipitation in methanol. The polymer was subsequently washed with copious amounts of hexanes and acetone. Final product was collected from Soxhlet with chloroform. PS relative $\mathrm{Mw}$ (GPC): $14 \mathrm{~kg} \mathrm{~mol}^{-1}$, polydispersity $=1.63 .{ }^{1} \mathrm{H}$ NMR $\left(500 \mathrm{MHz}, \mathrm{CDCl}_{3}\right)($ Fig. S2 $\dagger), \delta(\mathrm{ppm})$ : 7.5-7.8 (-Ar), $4.78\left(\mathrm{Ar}-\mathrm{CH}_{2}-\mathrm{OH}\right), 2.1\left(\mathrm{CH}_{2}-\mathrm{C}_{7} \mathrm{H}_{15}\right), 1.13\left(\mathrm{CH}_{2}{ }^{-}\right.$ $\left.\mathrm{C}_{5} \mathrm{H}_{10}-\mathrm{CH}_{3}\right), 0.80\left(\mathrm{C}_{7} \mathrm{H}_{14}-\mathrm{CH}_{3}\right)$.

General procedure for the preparation of UPy-end functionalized polymers. All UPy-end terminated polymers were prepared using the same procedure as described previously. ${ }^{25}$ In a representative procedure, $\mathrm{P} 3 \mathrm{HT}-\mathrm{OH}(300 \mathrm{mg}, 0.075 \mathrm{mmol}$ ), UPy-isocyanate $(65.9 \mathrm{mg}, 0.225 \mathrm{mmol})$ and 3 drops of dibutyltin dilaurate (DBDTL) were dissolved in dry $\mathrm{CHCl}_{3}$ and stirred at 50 ${ }^{\circ} \mathrm{C}$ for 24 hours. Silica gel (240 mesh, $10 \mathrm{mg}$ ) was subsequently added, and the solution was stirred at $60{ }^{\circ} \mathrm{C}$ for 24 hours. The crude product was precipitated in cold methanol, loaded into a Soxhlet apparatus, and washed with $\mathrm{CHCl}_{3}$ to collect the final product, which was concentrated under reduced pressure and dried under vacuum. ${ }^{1} \mathrm{H}$ NMR data for each polymer is provided in the text below and in the Fig. S3 and S4. $\dagger$ P3HT-UPy ${ }^{1} \mathrm{H}$ NMR $\left(500 \mathrm{MHz}^{\mathrm{CDCl}}{ }_{3}\right.$ ) (Fig. S3†), $\delta$ (ppm): $13.15(-\mathrm{NH}), 11.88(-\mathrm{NH})$, 10.18 (-NH), 5.82 (-CH on UPy), 7.0 (Ar-H), 4.4 (Ar-O- $\mathrm{CH}_{2}-\mathrm{CH}_{2}-$ UPy), 4.1 (Ar-O- $\left.\mathrm{CH}_{2}-\mathrm{CH}_{2}-\mathrm{OH}\right), 2.8\left(\mathrm{Ar}-\mathrm{CH}_{2}-\right), 2.49\left(\mathrm{Ar}-\mathrm{CH}_{3}\right), 1.7$ $\left(\mathrm{Ar}-\mathrm{CH}_{2}-\mathrm{CH}_{2}-\right)$, 1.2-1.5 (Ar- $\left.\mathrm{CH}_{2}-\mathrm{CH}_{2}-\left(\mathrm{CH}_{2}\right)_{3}-\mathrm{CH}_{3}\right), 0.9$ (Ar$\left(\mathrm{CH}_{2}\right)_{5}-\mathrm{CH}_{3}$ ). PFTBT-UPy ${ }^{1} \mathrm{H}$ NMR (500 MHz, $\mathrm{CDCl}_{3}$ ) (Fig. S4 $\dagger$ ), $\delta$ (ppm): $13.15(1 \mathrm{H} ;-\mathrm{NH}), 11.88(1 \mathrm{H} ;-\mathrm{NH}), 10.18(1 \mathrm{H},-\mathrm{NH})$, $5.82(1 \mathrm{H} ;-\mathrm{CH}), 7.5-7.8(-\mathrm{Ar}), 4.78\left(\mathrm{Ar}^{-} \mathrm{CH}_{2}-\mathrm{OH}\right), 2.1\left(\mathrm{CH}_{2}-\right.$ $\left.\mathrm{C}_{7} \mathrm{H}_{15}\right), 1.13\left(\mathrm{CH}_{2}-\mathrm{C}_{5} \mathrm{H}_{10}-\mathrm{CH}_{3}\right), 0.80\left(\mathrm{C}_{7} \mathrm{H}_{14}-\mathrm{CH}_{3}\right)$.

\section{Characterization}

Size exclusion chromatography (SEC). Molecular weights and polydispersities were obtained by SEC using an Agilent 1200 module equipped with three PSS SDV columns in series (100, 1000, and $10000 \AA$ pore sizes), an Agilent variable wavelength UV/visible detector, and a Wyatt Technology Optilab reX RI detector. This system enables SEC with simultaneous refractive index (SEC-RI) and UV-Vis detection. THF was used as the mobile phase at a flow rate of $1 \mathrm{~mL} \mathrm{~min}^{-1}$ at $40{ }^{\circ} \mathrm{C}$. Polystyrene relative molecular weights are calculated using Astra Software Version 5.3.4.

Nuclear magnetic resonance spectroscopy (NMR). ${ }^{1} \mathrm{H}$ NMR spectroscopy was performed on Varian $500 \mathrm{MHz}$. Samples were placed in $5 \mathrm{~mm}$ o.d. tubes with sample concentrations of about $5 \mathrm{mg} \mathrm{mL} \mathrm{m}^{-1}$. Solvents contain $0.05 \%$ TMS as an internal standard. Spectra were processed using ${ }^{1} \mathrm{D}$ NMR Processor in ACDLABS 12.0.

Fourier transform infrared (FTIR). FTIR analysis was carried out using a Thermo-Nicolet Nexus 670 instrument operated via the OMNIC program. Samples were prepared by depositing approximately $1 \mathrm{mg}$ of bulk polymer on the sample holder.

Cyclic voltammetry (CV). CV measurement was performed using CHI 620C Electrochemical Analyzer, CH Instruments. Sample solutions were prepared by adding trace amount of polymers in anhydrous $0.1 \mathrm{M}$ TBAP electrolyte $\mathrm{CHCl}_{3}$ solution. We used carbon as the working electrode, Pt wire as counter electrode and saturated $\mathrm{AgNO}_{3}$ as reference electrode. Equipment was calibrated with using ferrocence dissolved in $0.1 \mathrm{M}$ TBAP electrolyte $\mathrm{CHCl}_{3}$ solution. Sample solution was purged 
with $\mathrm{N}_{2}$ for 10 minutes before measurement. The CV curves and UV-Vis spectra for calculation of energy levels are provided in Fig. S6-S9. $\uparrow$ Calculation for energy levels followed the methods as reported previously. ${ }^{32}$ The estimation of HOMO level was done with the equation $E_{\mathrm{HOMO}}=\left[\left(E_{\mathrm{Ox}}-E_{1 / 2 \text { (ferrocene) }}\right)+4.8\right] \mathrm{eV}$, where the $E_{\text {red }}$ is the onset point of reduction potential and $E_{1 / 2 \text { (ferrocene) }}$ is the average of oxidation and reduction potentials from ferrocene. The band gap energy of polymers were calculated from the cross point of onset line and baseline of UV-Vis curves. The LUMO level is $E_{\text {HOMO }}$ subtracting the band gap energy.

Photovoltaic device fabrication and measurement. Photovoltaic devices were prepared with conventional structures of ITO/PEDOT:PSS (55 nm)/active layer $(80-90 \mathrm{~nm}) / \mathrm{Al}(100 \mathrm{~nm})$. ITO glass substrates $(20 \mathrm{ohm}$ per sq, $150 \mathrm{~nm}$, purchased from TFD Inc.) were rinsed with isopropanol, followed by 3 minutes ozone/plasma treatment. PEDOT:PSS (purchased from Sigma Aldrich) was spin-coated on top of ITO at $5000 \mathrm{rpm}$ for 40 seconds giving a film thickness about $55 \mathrm{~nm}$ measured by Bruker Dektak XT profilometer. The PEDOT:PSS/ITO substrates were thermal annealed at $120{ }^{\circ} \mathrm{C}$ for 10 minutes in air and then transferred to a argon-filled glovebox. Polymer solutions (total concentration is $7 \mathrm{mg} \mathrm{mL} \mathrm{mL}^{-1}$ ) were prepared with using anhydrous $\mathrm{CHCl}_{3}$ and stirred at room temperature for about 20 hours inside glovebox. After spin-coating active layer films, devices were completed by thermal evaporation of $100 \mathrm{~nm} \mathrm{Al}$ at $10^{-6}$ torr on top of the active layer through a shadow mask. The device area is $3.5 \mathrm{~mm}^{2}$. The integrated devices were further thermal annealed at different temperatures as noted in article. The power conversion efficiency (PCE) of the devices was measured in the air by Class AAA with AM 1.5 filter solar simulator at an intensity of $100 \mathrm{~mW} \mathrm{~cm} \mathrm{~cm}^{-2}$ (PV Measurements Inc.).

Atomic force microscopy (AFM). AFM analysis was performed using a Veeco Multimode 8 with NanoScope V Controller (instruments located at the Rice University). Sample topography was recorded using ScanAsyst ${ }^{\mathrm{TM}}$ mode. $2^{\text {nd }}$ order flattening was used for compensation of sample tilt and enhancement of image contrast.

Impedance spectroscopy (IS). IS measurement was performed using Autolab PGSTAT302N with program NOVA 1.10 on the same devices as device measurement. The frequency was used in the range of $0.1 \mathrm{~Hz}$ to $10^{6} \mathrm{~Hz}$ without applying bias. Fiber-Lite model 190 was used for illumination. Data were analyzed with using Zview.

\section{Results and discussion}

We chose P3HT and PFTBT conjugated polymers as a model system to investigate the effect of hydrogen bonding associations, specifically 2-ureido- $4[1 H]$-pyrimidinone (UPy) on both polymer-blend OPVs. The chemical structures of the UPyfunctionalized polymers are shown in Fig. 1(a). This combination of polymers has been previously studied in both blends $\mathrm{s}^{\mathbf{5 , 6 , 3 3}}$ and block copolymers ${ }^{34}$ and serves as a useful model system to explore a generally applicable approach that can be applied to further improve high-performance polymer blend systems. In
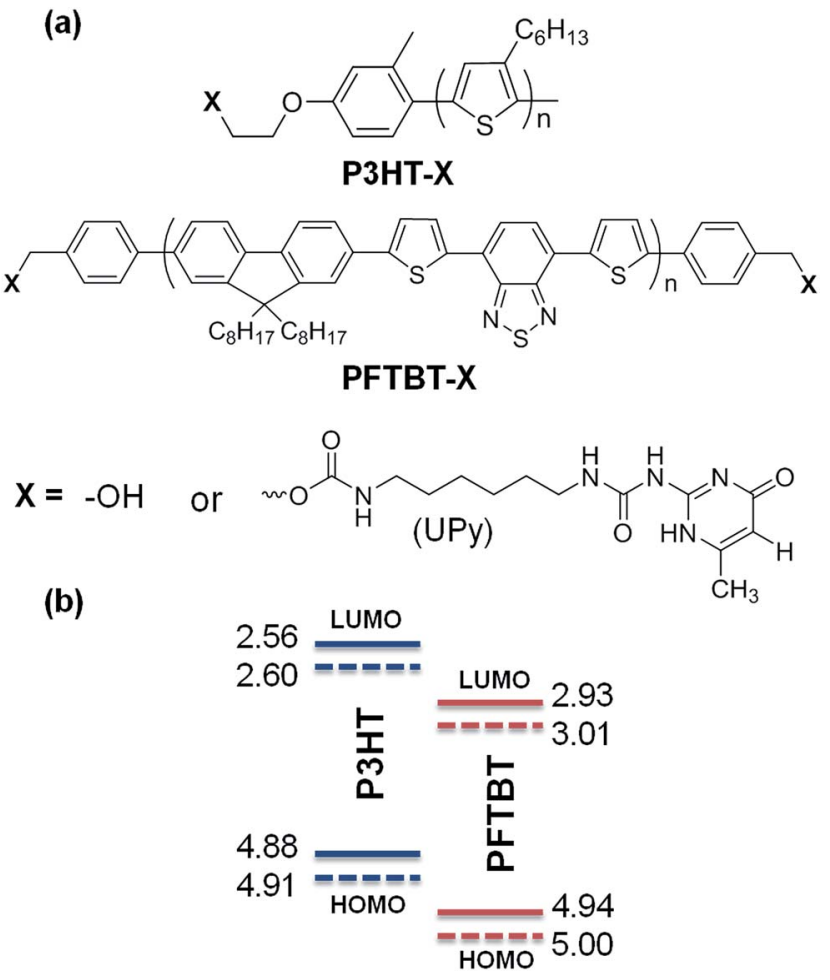

Fig. 1 (a) Chemical structures for $\mathrm{OH}$ - and UPy-terminated P3HT and PFTBT and (b) energy level diagram (in eV) of OH-terminated (solid lines) and UPy-terminated (dash lines) P3HT and PFTBT.

order to prepare UPy-functionalized P3HT, we utilized an externally initiated polymerization reaction to first synthesize hydroxylterminated P3HT ${ }^{31,35}$ which was subsequently coupled to UPy group through reaction with an isocyanate functionality. ${ }^{25}{ }^{1} \mathrm{H}$ NMR analysis proves the incorporation of the UPy group, with distinct peaks in the ${ }^{1} \mathrm{H}$ NMR spectra (see ESI Fig. S1 and S2 $\dagger$ ). UPyfunctionalized PFTBT was similarly prepared through the use of an endcapping molecule to yield hydroxyl-functionalized PFTBT followed by reaction with UPy with an isocyanate functionality. ${ }^{1} \mathrm{H}$ NMR analysis of the functionalized PFTBT reveals peaks corresponding to the UPy endgroup (see ESI Fig. S3 and S4†). Additionally, FTIR analysis (see ESI Fig. S5 $\dagger$ ) shows that the peak near $3450 \mathrm{~cm}^{-1}$ corresponding to the hydroxyl functional group disappears after reaction with the UPy hydrogen bonding group.

Hydroxyl- and UPy end-capped polymers were analyzed by cyclic voltammetry and UV-Vis absorbance analysis to obtain the highest occupied molecular orbital (HOMO) and lowest unoccupied molecular orbital (LUMO) energy levels. As shown in Fig. 1(b), the energy levels of UPy-terminated polymers decrease slightly relative to unmodified polymers due to the strong electron affinity of the UPy group. A drop is seen for both P3HT and PFTBT, but the bandgap for each polymer and the HOMO/LUMO offset of the combination is roughly unchanged (see ESI Fig. S6-S9† for cyclic voltammetry measurements).

\section{OPV device fabrication and testing}

We prepared BHJ OPV devices by blending and spin-coating polymer blends onto a surface. An advantage of 
supramolecular block copolymer systems relative to covalent block copolymers is that the composition can be varied through simple solution blending. P3HT and PFTBT were dissolved in a nonpolar solvent (chloroform) at a desired ratio and stirred overnight to allow sufficient time for supramolecular associations. We tested a series of blending ratios and found that the optimal device performance was achieved at a 1:1 ratio of P3HT-UPy to PFTBT-UPy (see ESI Fig. S10†).

Using this optimal composition, supramolecular OPV devices were compared with non-modified P3HT/PFTBT blend OPVs under two different post-processing annealing temperatures: $100{ }^{\circ} \mathrm{C}$ and $155{ }^{\circ} \mathrm{C}$. Prior work has shown that higher annealing temperatures can improve $\mathrm{P} 3 \mathrm{HT}$ charge mobilities ${ }^{36}$ but can also result in large-scale phase separation in polymer/ polymer blends. ${ }^{10,33,37}$ In hydrogen bonding supramolecular block copolymers, we have found that hydrogen bonding associations can prevent macroscopic phase separation at annealing temperatures as high as $160^{\circ} \mathrm{C} .{ }^{25}$ As shown in Fig. 2 and Table 1 , non-associative P3HT-OH/PFTBT-OH blends exhibit decreased performance at higher annealing temperatures, $0.43 \%$ power conversion efficiency (PCE) at $155^{\circ} \mathrm{C}$ compared with $0.62 \%$ PCE at $100{ }^{\circ} \mathrm{C}$, primarily due to a drop in the short-circuit current $J_{\mathrm{sc}}$.

\section{(a) Annealed at $100^{\circ} \mathrm{C}$}

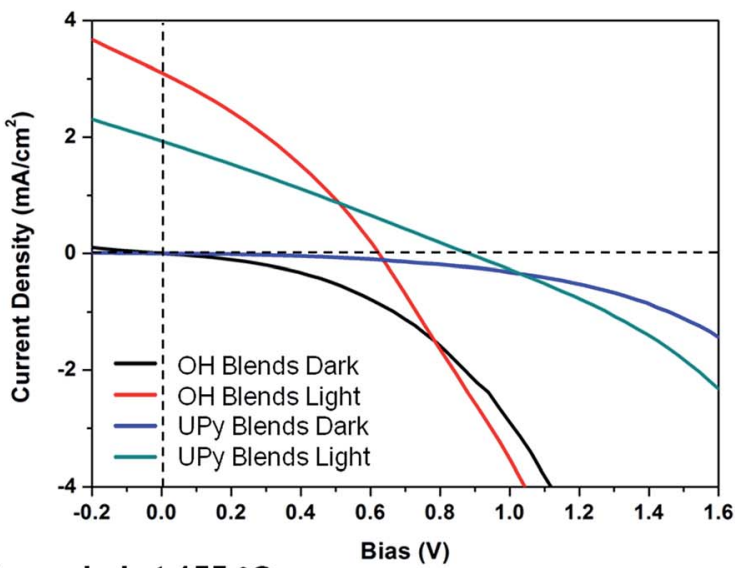

(b) Annealed at $155^{\circ} \mathrm{C}$

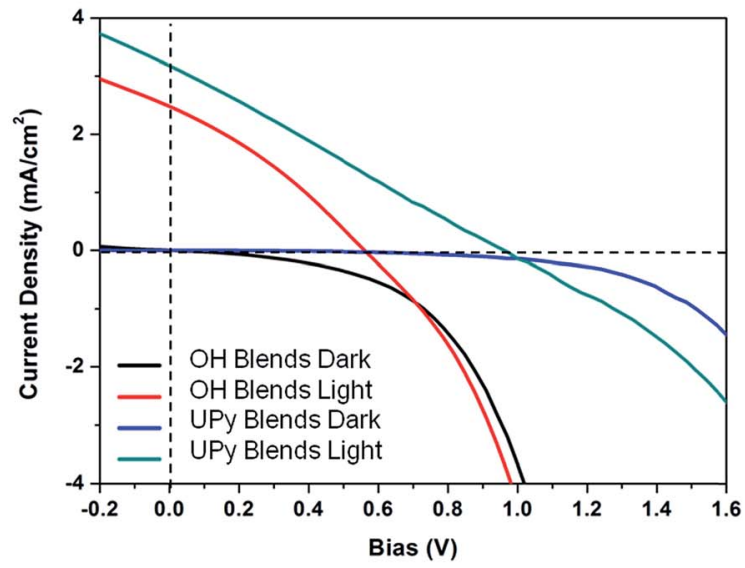

Fig. 2 OPV device $/-V$ curves for P3HT/PFTBT $(1: 1 \mathrm{w} / \mathrm{w})$ with thermal annealing at (a) $100^{\circ} \mathrm{C}$ and (b) $155^{\circ} \mathrm{C}$. Device $I-V$ curves are plotted for comparison between $\mathrm{OH}$ - or UPy-terminated polymers.
Table 1 OPVs characteristics ${ }^{a}$ for P3HT/PFTBT $(1: 1 \mathrm{w} / \mathrm{w})$

\begin{tabular}{lllll}
\hline Active layer & $\begin{array}{l}\text { PCE } \\
{[\%]}\end{array}$ & $\left.\begin{array}{l}J_{\text {sc }} \\
{[\mathrm{mA} \mathrm{cm}}\end{array}{ }^{-2}\right]$ & $\begin{array}{l}V_{\text {oc }} \\
{[\mathrm{V}]}\end{array}$ & FF \\
\hline P3HT-OH/PFTBT-OH $\left(100^{\circ} \mathrm{C}\right)$ & 0.62 & 3.10 & 0.62 & 0.32 \\
P3HT-UPy/PFTBT-UPy $\left(100^{\circ} \mathrm{C}\right)$ & 0.45 & 1.93 & 0.88 & 0.26 \\
P3HT-OH/PFTBT-OH $\left(150^{\circ} \mathrm{C}\right)$ & 0.43 & 2.48 & 0.56 & 0.31 \\
P3HT-UPy/PFTBT-UPy $\left(150^{\circ} \mathrm{C}\right)$ & 0.77 & 3.18 & 0.96 & 0.25
\end{tabular}

${ }^{a}$ Average over 8 devices. PCE: power conversion efficiency; $J_{\mathrm{sc}}$ : short circuit current; $V_{\mathrm{oc}}$ : the open-circuit voltage; FF: fill factor.

Conversely, supramolecular OPVs with P3HT-UPy/PFTBT-UPy blends exhibit improved performance at elevated annealing temperatures, with PCE increased from $0.45 \%$ to $0.77 \%$ and an increased short circuit current from $1.93 \mathrm{~mA} \mathrm{~cm} \mathrm{~cm}^{-2}$ to $3.18 \mathrm{~mA}$ $\mathrm{cm}^{-2}$. This indicates a suppression of large-scale separation and improved charge mobility at elevated annealing temperatures for supramolecular blends. P3HT-UPy/PFTBT-UPy devices also have higher open-circuit voltage compared with P3HT-OH/ PFTBT-OH devices under both annealing conditions. On the other hand, the fill factor for devices from UPy-modified polymer blends is lower than that non-modified polymer blends under both different annealing conditions. We hypothesize that the introduction of hydrogen bonding may increase the charge transport resistance, and investigate this through impedance spectroscopy measurements described below. We also note that the low PCE of the current polymer blend systems is likely due to the lower molecular weight of our polymers compared with those studied previously. ${ }^{5}$ Nevertheless, our results point to clear benefits of hydrogen bonding associations.

\section{Morphological analysis}

AFM was performed to elucidate the morphological difference in associative and non-associative P3HT/PFTBT blend devices as well as the effects of annealing temperatures in polymer blends. In the case of unmodified P3HT/PFTBT blends, films annealed at $155{ }^{\circ} \mathrm{C}$ (Fig. 3(b)) are less uniform (larger RMS roughness number) in comparison with films annealed at $100{ }^{\circ} \mathrm{C}$ (Fig. 3(a)). By comparison, films of hydrogen-bonding associative polymers exhibit significantly improved uniformity at both annealing temperatures relative to non-modified polymer blends. The overall lower performance for hydrogen-bond associating polymers annealed at $100{ }^{\circ} \mathrm{C}$ may be due improved miscibility and reduced pathways for charge transport. However, UPy-modified polymer blend devices annealed at $155{ }^{\circ} \mathrm{C}$ exhibit both improved miscibility and long-range ordering of P3HT crystallites, ${ }^{38}$ and as discussed above this results in superior performance in UPy-modified polymer blend devices relative to the non-modified polymer blends when annealed at $155^{\circ} \mathrm{C}$.

\section{Impedance analysis}

Impedance spectroscopy was used to gain further insight on the electrical properties of our polymer blends and its impact on 

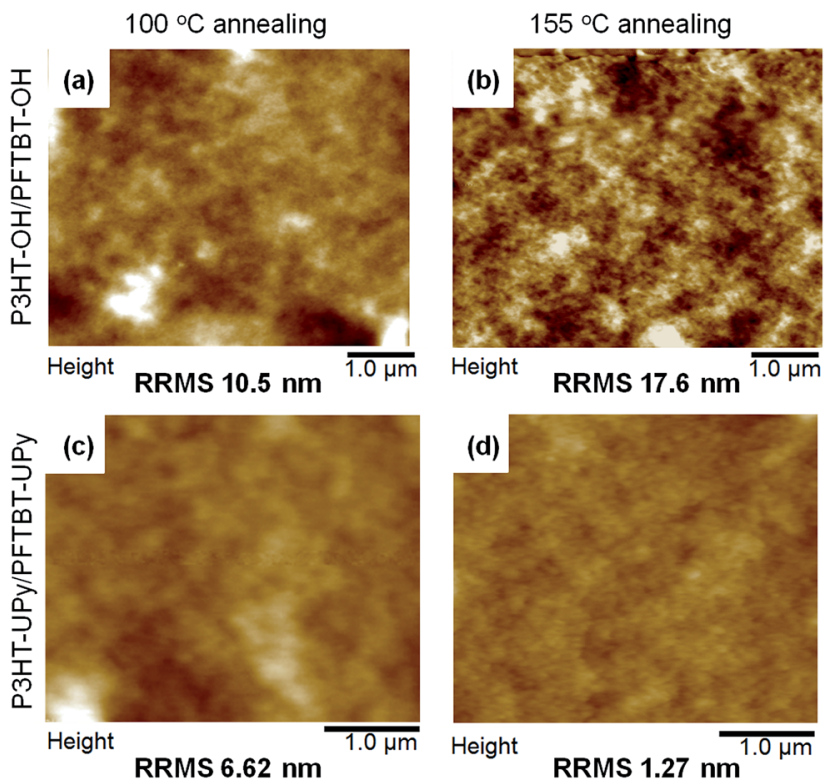

Fig. 3 AFM height images on the P3HT-OH/PFTBT-OH devices: annealed at (a) $100{ }^{\circ} \mathrm{C}$ and (b) $155^{\circ} \mathrm{C}$; P3HT-UPy/PFTBT-UPy devices: annealed at (c) $100{ }^{\circ} \mathrm{C}$, and (d) $155^{\circ} \mathrm{C}$. RRMS stands for root-meansquare roughness.

photovoltaic performance. Impedance spectroscopy is commonly used to understand the properties of internal interfaces and device components. ${ }^{39-41}$ Impedance analysis has also been applied to analyze $\mathrm{BHJ} \mathrm{OPVs}^{42,43}$ and correlate impedance behavior of P3HT/PCBM devices with active layer composition and processing history by using a simplified equivalent circuit model (see ESI Fig. S11 $\dagger$ ). ${ }^{\mathbf{4 4 , 4 5}}$ We apply this model to estimate the bulk resistance $\left(R_{1}\right)$ of the active layer by analyzing the high frequency arc for resistance across electrodes and the recombination resistance $\left(R_{2}\right)$ at the donor-acceptor interface by analyzing the low frequency arc from the Cole-Cole plots (see ESI Fig. S12 $\dagger$ ). Lower $R_{1}$ and larger $R_{2}$ are preferred for enhanced charge transport across the active layer and can reduce the accumulation of trapped charges. ${ }^{45-47}$ We focus on analysis of $R_{1}$ and $R_{2}$ under zero voltage-bias conditions to understand the roles of biomolecular recombination and charge transport within the active layer. ${ }^{\mathbf{4 4 8}}$ Here, our measurement of $R_{1}$ and $R_{2}$ parameters can provide information on how hydrogen bonding interactions influence device characteristics and interface properties.

As presented in Fig. 4, for the unmodified polymer blend (P3HT-OH/PFTBT-OH) devices, the bulk resistance $R_{1}$ for devices annealed at $155{ }^{\circ} \mathrm{C}$ is about quadruple that for devices annealed at $100{ }^{\circ} \mathrm{C}$. This is consistent with macrophase separation at elevated annealing temperatures, as shown in Fig. 3(b). Interestingly, the recombination resistance $R_{2}$ for devices annealed at $155{ }^{\circ} \mathrm{C}$ is also higher than that for devices annealed at $100{ }^{\circ} \mathrm{C}$. This may be because macroscopic phase separation produces purer domains, which is known to reduce charge recombination. ${ }^{49}$ On the other hand, for hydrogen-bond associating blends P3HT-UPy/PFTBT-UPy, bulk resistance $R_{1}$ is smaller and recombination resistance $R_{2}$ is higher for devices

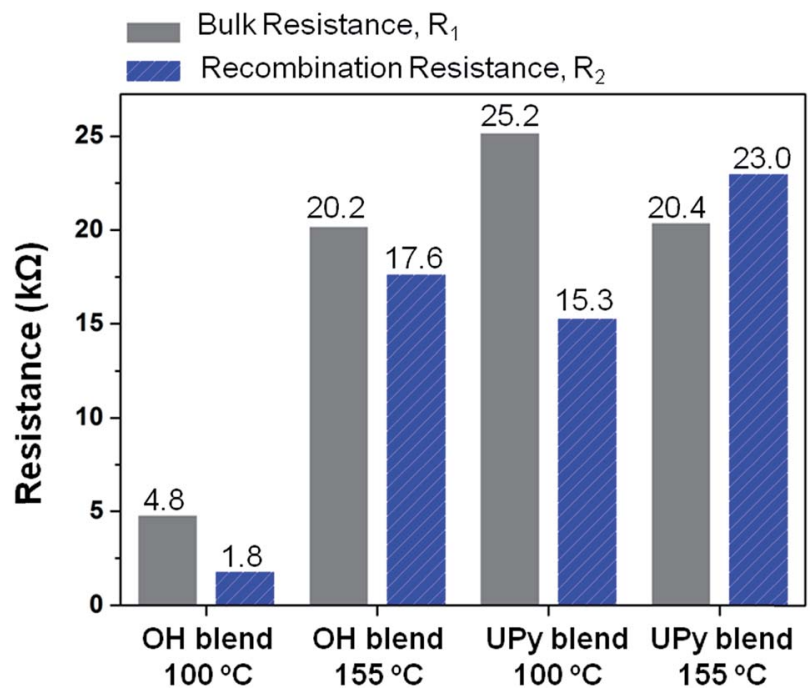

Fig. 4 Bulk resistance $\left(R_{1}\right)$ and recombination resistance $\left(R_{2}\right)$, that are extracted from Cole-Cole plots for P3HT/PFTBT devices under illumination condition at $\mathrm{O} \mathrm{V}$ bias.

annealed at $155^{\circ} \mathrm{C}$ compared with those annealed $100{ }^{\circ} \mathrm{C}$. This strongly supports the morphological studies and suggests that hydrogen-bonding associations decrease bulk resistance (due to reduces macrophase separation) and charge accumulation at interfaces.

Comparing non-modified and UPy-modified polymer blend devices, we see that the hydrogen bonding endgroup increases both the bulk resistances $R_{1}$ and interfacial resistance $R_{2}$. The increased interfacial resistance is desirable and results in more efficient charge separation when UPy groups are present. However, the increase in $R_{1}$ is undesirable and explains why there is only a small improvement in device performance with the incorporation of UPy endgroups. Previous research has shown that the series resistance including active layer resistances, electrode resistances and contact resistance has a pronounced effect on fill factor but only a limited effect on short-circuit current. ${ }^{50}$ Here, we observed a higher short-circuit current lower fill factor in UPy-modified polymer blend devices annealed at $155{ }^{\circ} \mathrm{C}$. Although we demonstrate improved photovoltaic device performance with using hydrogen bonding interaction, our work presents a trade-off in the use of hydrogen boding-mediated associations with improved charge separation at interfaces but increased bulk resistance.

\section{Conclusions}

We explored the use of the UPy quadruple hydrogen bonding group to manipulate the morphologies and interfacial properties of polymer/polymer blends BHJ OPVs. We analyzed film morphologies and impedance spectroscopy to understand how the hydrogen bonding group influences morphology and device characteristics. We found a small enhancement in the power conversion efficiency on annealed OPVs, and impedance analysis of polymer-blend OPVs revealed an increase in both charge transport and charge recombination resistance. Thus, this work 
demonstrates that while hydrogen bonding interactions mediated by terminal UPy functional groups are an effective way to reduce macro-phase separation in polymer/polymer blends, optimization of interfacial electronic properties is also needed to produce high-performance photovoltaic devices.

\section{Acknowledgements}

This work was carried out with support from the National Science Foundation (CBET - 1264703 and DMR-1352099), the Welch Foundation for Chemical Research (grant \# R4940S) and Louis and Peaches Owen. The work at Los Alamos National Laboratory (LANL) was supported by DoE Office of Basic Energy Sciences Work Proposal 08SPCE973 (W. N. and A. D. M.) and by the LANL LDRD program XW11 (A. D. M.). This work was performed, in part, at the Center for Integrated Nanotechnologies. Los Alamos National Laboratory, an affirmative action equal opportunity employer, is operated by Los Alamos National Security, LLC, for the National Nuclear Security Administration of the U.S. Department of Energy under contract DE-AC5206NA25396.

\section{Notes and references}

1 K. M. Coakley and M. D. McGehee, Chem. Mater., 2004, 16, 4533-4542.

2 A. Facchetti, Mater. Today, 2013, 16, 123-132.

3 M. C. Scharber and N. S. Sariciftci, Prog. Polym. Sci., 2013, 38, 1929-1940.

4 C. R. McNeill and N. C. Greenham, Adv. Mater., 2009, 21, 3840-3850.

5 D. Mori, H. Benten, H. Ohkita, S. Ito and K. Miyake, ACS Appl. Mater. Interfaces, 2012, 4, 3325-3329.

6 D. Mori, H. Benten, J. Kosaka, H. Ohkita, S. Ito and K. Miyake, ACS Appl. Mater. Interfaces, 2011, 3, 2924-2927.

7 R. Steyrleuthner, R. Di Pietro, B. A. Collins, F. Polzer, S. Himmelberger, M. Schubert, Z. Chen, S. Zhang, A. Salleo, H. Ade, A. Facchetti and D. Neher, J. Am. Chem. Soc., 2014, 136, 4245-4256.

8 T. Earmme, Y.-J. Hwang, S. Subramaniyan and S. A. Jenekhe, Adv. Mater., 2014, 26, 6080-6085.

9 P. Cheng, L. Ye, X. Zhao, J. Hou, Y. Li and X. Zhan, Energy Environ. Sci., 2014, 7, 1351-1356.

10 C. R. McNeill, A. Abrusci, I. Hwang, M. A. Ruderer, P. MüllerBuschbaum and N. C. Greenham, Adv. Funct. Mater., 2009, 19, 3103-3111.

11 H. Kang, M. A. Uddin, C. Lee, K.-H. Kim, T. L. Nguyen, W. Lee, Y. Li, C. Wang, H. Y. Woo and B. J. Kim, J. Am. Chem. Soc., 2015, 137, 2359-2365.

12 Y.-J. Hwang, T. Earmme, B. A. E. Courtright, F. N. Eberle and S. A. Jenekhe, J. Am. Chem. Soc., 2015, 137, 4424-4434.

13 C. Mu, P. Liu, W. Ma, K. Jiang, J. Zhao, K. Zhang, Z. Chen, Z. Wei, Y. Yi, J. Wang, S. Yang, F. Huang, A. Facchetti, H. Ade and H. Yan, Adv. Mater., 2014, 26, 7224-7230.

14 D. Mori, H. Benten, I. Okada, H. Ohkita and S. Ito, Adv. Energy Mater., 2014, 4, 1301006-1301011.
15 Z. Lu, B. Jiang, X. Zhang, A. Tang, L. Chen, C. Zhan and J. Yao, Chem. Mater., 2014, 26, 2907-2914.

16 Y.-J. Hwang, B. A. E. Courtright, A. S. Ferreira, S. H. Tolbert and S. A. Jenekhe, Adv. Mater., 2015, 27, 4578-4584.

17 J. Emsley, Chem. Soc. Rev., 1980, 9, 91-124.

18 L. J. Prins, D. N. Reinhoudt and P. Timmerman, Angew. Chem., Int. Ed., 2001, 40, 2382-2426.

19 E. D. Glowacki, M. Irimia-Vladu, S. Bauer and N. S. Sariciftci, J. Mater. Chem. B, 2013, 1, 3742-3753.

20 R. Abbel, C. Grenier, M. J. Pouderoijen, J. W. Stouwdam, P. Leclere, R. P. Sijbesma, E. W. Meijer and A. Schenning, J. Am. Chem. Soc., 2009, 131, 833-843.

21 R. Abbel, A. Schenning and E. W. Meijer, J. Polym. Sci., Part A: Polym. Chem., 2009, 47, 4215-4233.

22 Y. Lin, Q. Wei, G. Qian, L. Yao and J. J. Watkins, Macromolecules, 2012, 45, 8665-8673.

23 S.-L. Hsu, C.-M. Chen, Y.-H. Cheng and K.-H. Wei, J. Polym. Sci., Part A: Polym. Chem., 2011, 49, 603-611.

24 A. P. H. J. Schenning, J. V. Herrikhuyzen, P. Jonkheijm, Z. Chen, F. Würthner and E. W. Meijer, J. Am. Chem. Soc., 2002, 124, 10252-10253.

25 Y.-H. Lin, S. B. Darling, M. P. Nikiforov, J. Strzalka and R. Verduzco, Macromolecules, 2012, 45, 6571-6579.

26 F. Li, K. G. Yager, N. M. Dawson, Y.-B. Jiang, K. J. Malloy and Y. Qin, Chem. Mater., 2014, 26, 3747-3756.

27 H. J. Kim, J.-H. Kim, J.-H. Ryu, Y. Kim, H. Kang, W. B. Lee, T.-S. Kim and B. J. Kim, ACS Nano, 2014, 8, 10461-10470.

28 B. J. B. Folmer, R. P. Sijbesma, R. M. Versteegen, J. A. J. van der Rijt and E. W. Meijer, Adv. Mater., 2000, 12, 874-878.

29 Y.-K. Han, Y.-J. Lee and P.-C. Huang, J. Electrochem. Soc., 2009, 156, k37-k43.

30 K. A. Smith, D. L. Pickel, K. Yager, K. Kisslinger and R. Verduzco, J. Polym. Sci., Part A: Polym. Chem., 2014, 52, 154-163.

31 C. N. Kempf, K. A. Smith, S. L. Pesek, X. Li and R. Verduzco, Polym. Chem., 2013, 4, 2158-2163.

32 A. Shafiee, M. M. Salleh and M. Yahaya, Sains Malays., 2011, 40(2), 173-176.

33 C. R. McNeill, J. J. M. Halls, R. Wilson, G. L. Whiting, S. Berkebile, M. G. Ramsey, R. H. Friend and N. C. Greenham, Adv. Funct. Mater., 2008, 18, 2309-2321.

34 C. Guo, Y.-H. Lin, M. D. Witman, K. A. Smith, C. Wang, A. Hexemer, J. Strzalka, E. D. Gomez and R. Verduzco, Nano Lett., 2013, 13, 2957-2963.

35 H. A. Bronstein and C. K. Luscombe, J. Am. Chem. Soc., 2009, 131, 12894-12895.

36 V. D. Mihailetchi, H. X. Xie, B. de Boer, L. J. A. Koster and P. W. M. Blom, Adv. Funct. Mater., 2006, 16, 699-708.

37 R. C. Mulherin, S. Jung, S. Huettner, K. Johnson, P. Kohn, M. Sommer, S. Allard, U. Scherf and N. C. Greenham, Nano Lett., 2011, 11, 4846-4851.

38 G. Li, V. Shrotriya, Y. Yao and Y. Yang, J. Appl. Phys., 2005, 98, 043704.

39 J. Bisquert, F. Fabregat-Santiago, I. Mora-Seró, G. GarciaBelmonte and S. Giménez, J. Phys. Chem. C, 2009, 113, 17278-17290. 
40 I. Mora-Seró, J. Bisquert, F. Fabregat-Santiago, G. GarciaBelmonte, G. Zoppi, K. Durose, Y. Proskuryakov, I. Oja, A. Belaidi, T. Dittrich, R. Tena-Zaera, A. Katty, C. LévyClément, V. Barrioz and S. J. C. Irvine, Nano Lett., 2006, 6, 640-650.

41 C. Longo, A. F. Nogueira, M.-A. De Paoli and H. Cachet, J. Phys. Chem. B, 2002, 106, 5925-5930.

42 G. Garcia-Belmonte, P. P. Boix, J. Bisquert, M. Sessolo and H. J. Bolink, Sol. Energy Mater. Sol. Cells, 2010, 94, 366-375. 43 G. Garcia-Belmonte, A. Munar, E. M. Barea, J. Bisquert, I. Ugarte and R. Pacios, Org. Electron., 2008, 9, 847-851.

44 B. J. Leever, C. A. Bailey, T. J. Marks, M. C. Hersam and M. F. Durstock, Adv. Energy Mater., 2012, 2, 120-128.
45 Y. Aoyama, T. Yamanari, N. Ohashi, Y. Shibata, Y. Suzuki, J. Mizukado, H. Suda and Y. Yoshida, Sol. Energy Mater. Sol. Cells, 2014, 120, 584-590.

46 A. Seemann, T. Sauermann, C. Lungenschmied, O. Armbruster, S. Bauer, H. J. Egelhaaf and J. Hauch, Sol. Energy, 2011, 85, 1238-1249.

47 J. Schafferhans, A. Baumann, A. Wagenpfahl, C. Deibel and V. Dyakonov, Org. Electron., 2010, 11, 1693-1700.

48 P. E. Keivanidis, T. M. Clarke, S. Lilliu, T. Agostinelli, J. E. Macdonald, J. R. Durrant, D. D. C. Bradley and J. Nelson, J. Phys. Chem. Lett., 2010, 1, 734-738.

49 C. Groves, R. A. Marsh and N. C. Greenham, J. Chem. Phys., 2008, 129, 114903.

50 J. D. Servaites, S. Yeganeh, T. J. Marks and M. A. Ratner, Adv. Funct. Mater., 2010, 20, 97-104. 